\title{
A Pedagogia do Oprimido em Tempos de Industrialização da Cultura
}

\author{
Antonio Alvaro Soares Zuin
}

Universidade Federal de São Carlos (UFScar)

Objetiva discutir conceitos da Pedagogia do Oprimido, no contexto da consolidação da indústria cultural no Brasil. "Hospedagem do opressor ", "ser mais e ser menos", "opressores e oprimidos ", "cultura popular e adtura erudita " são conceitos que precisam ser reinvestigados. O estudo torna-se relevante, sobretudo pelo fato de que a padronização da produção simbólica bem como a universalização da lógica do equivalente intensificam os comportamentos dos indivíduos, que atenuam, de forma ilusória, suas debilidades, uma vez que se identificam como consumidores.

\section{Introdução}

Quando estudamos teorias e metodologias pedagógicas, nacionais ou internacionais, dificilmente deixamos de fazer referência à proposta pedagógica denominada Pedagogia do Oprimido, desenvolvida por Paulo Freire. Tal proposta foi e continua sendo objeto de estudo de vários pesquisadores, além de influenciar há décadas o pensamento e a praxis educacional direta ou indiretamente. E notável o reconhecimento nacional e internacional alcançado pela difusão dos seus pressupostos teóricos. No Brasil, nomes como Vanilda Paiva (1986) e Moacir Gadotti (1988), entre outros, representam uma ampla gama de pensadores que refletem sobre os conceitos produzidos por Paulo Freire. No exterior, para citar 
apenas alguns exemplos, Henry Giroux (1986), na denominada Pedagogia Radical, criada, ao seu ver, para superar os pressupostos teóricos das denominadas teorias da reprodução, baliza-se em conceitos elaborados pelos frankfurtianos, por Gramsci e por Paulo Freire. O pensador brasileiro também é reconhecido por Schmied-Kowarzik (1993), como sendo um teórico que elaborou uma experiência educacional dialética.

Além dessa repercussão, não menos impressionante foi a aplicação de um método de alfabetização que conseguiu alcançar resultados, tais como os das experiências de alfabetização de adultos realizadas em Angicos (RN), em 1962, onde 300 trabalhadores foram alfabetizados em 45 dias. Destaca-se também a tentativa de alfabetização em massa realizada pelo Mobral em 1967, utilizando-se do método de alfabetização de adultos criado por Freire. Contudo, seus idealizadores cometeram o equívoco de acreditar que é possível educar o cidadão à revelia da situação econômicopolítica do país.

De fato, divulgou-se que o Mobral utilizou a "técnica" de Paulo Freire, como se fosse possível destilar desse movimento de educação de adultos uma essência técnica neutra (cf. Buffa e Nosella, 1991, p.145). Na realidade, essa tentativa frustrada não faz mais do que deixar vislumbrar, no seu fracasso, as características fundamentais da Pedagogia do Oprimido. Por meio de uma proposta alfabetizadora, baseada na escolha de palavras geradoras que reverberavam as relações entre os analfabetos e suas próprias condições de vida, tinha-se como principal objetivo a conscientização do homem enquanto sujeito histórico. Esse homem seria capaz de reconhecer sua posição enquanto membro marginalizado, inserido num contexto de dominação e de exploração de classes sociais com interesses antagônicos. Esse texto, de caráter introdutório, possui como objetivo discutir alguns conceitos elaborados pelo educador, principalmente em função das transformações culturais sucedidas no Brasil por meio da consolidação do mercado de produtos simbólicos, ou seja, da indústria cultural. 


\section{A pedagogia do oprimido: uma pedagogia da praxis}

A proposta pedagógica objetiva fornecer condições para que o indivíduo marginalizado, mediante a participação nos círculos e centros de cultura, deixe de ser objeto e se transforme em sujeito da história. A intenção de Freire, que abarca também seu método de alfabetização, centrase na educação para a liberdade. Tal propósito reflete a preocupação central de possibilitar condições facilitadoras que permitam fazer com que o oprimido tome cada vez mais ciência de quais são os seus papéis, visando à transformação das suas condições de vida. Os oprimidos possuem o direito e o dever de lutarem pela real e efetiva apropriação daquelas objetivações humanas, tais como a ciência e a tecnologia, que são patrimônio de toda a humanidade, e não privilégio de grupos e/ou classes hegemônicas.

Em obras tais como: A pedagogia do oprimido (1979), Ação cultural para a liberdade (1987), Educação como prática da liberdade ( 1991 ), Educação e mudança ( 1986), Medo e ousadia (1987) e Pedagogia da esperança ( 1993), Paulo Freire destaca várias vezes os obstáculos que impedem o oprimido de se reconhecer enquanto tal e, mediante o exercício da ação refletida (praxis), transformar sua própria situação de dominação. De acordo com esse raciocínio, a condição do oprimido vir a ser sujeito está intimamente relacionada à necessidade de que o momento da consciência e da vontade seja prolongado durante a história. No prolongamento da própria consciência de si, observam-se homens que gradativamente vão se transformando em sujeitos, pois se tornam cada vez mais capazes de decodificar suas relações entre si e com o mundo, pronunciando-o de maneira verdadeira e desvelando os condicionantes sociais mitifícadores.

Na elaboração do conceito de praxis, Paulo Freire já observa a não-absolutização tanto da teoria como da prática (cf. Freire, 1979, p.92). O educador consegue dar origem a uma série de conceitos que se 
encontram imanentemente consubstanciados com a prática educacional, na luta pela formação de agentes educacionais. Além do fato de que a apropriação dos objetos cognoscíveis balize-se numa relação dialógica marcada pela continuidade e pela temporalidade, pode-se também observar os conceitos de hospedagem do opressor e de sombra. Tais conceitos referem-se à constatação de Paulo Freire de que os oprimidos são indivíduos que se caracterizam por vivenciarem situações ambíguas, uma vez que introjetam prescrições dos opressores e, sem que se apercebam disso, abrigam dentro de si o próprio dominador - ou sua sombra - , ao mesmo tempo em que não deixam de ser oprimidos.

Esses conceitos são relevantes, principalmente quando se possui a intenção de desvelar os mecanismos que fazem com que os próprios oprimidos participem ativamente do seu processo de desumanização. Tal fato torna-se evidente, na medida em que Paulo Freire faz alusão aos desejos de muitos oprimidos que, ao invés de lutarem pela libertação de si mesmos e dos próprios opressores, preferem se transformar em novos opressores. Algumas vezes, a introjeção dessas prescrições torna-se tão presente que qualquer atitude que possa redundar na denúncia da barbárie acaba por gerar um receio muito grande, ou mesmo aquilo que Freire denominou de medo da liberdade. Nos oprimidos, o medo parece ser decorrente da perspectiva de que eles mesmos possam ser livres. Assim, o inédito viável fica cada vez mais inviável. A adaptação é tão brutal que parece obstaculizar a própria organização dos oprimidos em grupos reivindicatórios. Apesar dessa constatação, talvez o processo de introjeção de normas e valores condizentes com a manutenção da barbárie social não encontre melhor caracterização do que a seguinte asserção do educador:

Submetidos ao condicionamento de uma cultura do êxito e do sucesso pessoal, reconhecer-se numa situação objetiva desfavorável, para uma consciência alienada, é freiar a própria possibilidade de êxito (Freire, 1979, p. 184).

São notórios os casos de professores que, em muitas ocasiões, não possuem consciência da forma como seus próprios preconceitos estão 
arraigados nas suas estruturas de personalidade. São atitudes cotidianas dos mestres aquelas que imputam as dificuldades dos alunos das classes marginalizadas em aprender a lição às suas "naturezas arredias". Por sua vez, esses alunos, de forma geral, acabam interiorizando essa mensagem de incompetência, que é transmitida direta ou veladamente, auxiliando a própria reprodução das práticas preconceituosas e do processo de violência simbólica a que estão submetidos, sem que tenham consciência disso. Uma defesa freqüentemente utilizada é a da racionalização, que funciona como uma espécie de justificativa feita pelo próprio oprimido, a fim de propiciar uma explicação pelo seu "fracasso", obnubilando os condicionantes sociais objetivos, responsáveis pelo processo de desumanização.

Um modelo de educação que corresponderia a uma situação como essa é o da educação bancária. De acordo com Paulo Freire, as escolas são marcadas por um processo de ensino-aprendizagem, realizado na forma de atividades de narração e de dissertação, mediante a transmissão de conhecimentos por parte do educador. É central para esse modelo de educação a memorização mecânica de objetos cognoscíveis. A educação transforma-se num mero ato de depósito de conhecimentos, daí a alusão aos bancos.

Como contraponto a esse modelo, o educador faz referência à educação problematizadora. Tal educação não se caracteriza pelo mero ato de transmissão de conhecimentos, como se o processo de ensinoaprendizagem fosse reduzido a uma rua de mão única. $\mathrm{O}$ processo fundamenta-se, sim, na Veiculação de juízos Je valor por parte dos agentes educacionais (cf. Freire, 1979, p.78). Seguindo esta linha de raciocínio, a educação só poderia mesmo se fundamentar no diálogo entre os agentes educacionais. A pronúncia do mundo e das relações entre os homens é condição sine qua non para o próprio processo de humanização e de construção das identidades:

O Mundo pronunciado, por sua vez, se volta problematizado aos sujeitos pronunciantes, a exigir novas pronúncias... Os homens se fazem homens na palavra, no trabalho, na ação-reflexão (Freire, 1979, p.92-93). 
Em linhas gerais, esses são alguns dos conceitos produzidos por Paulo Freire na criação de uma teoria relacionada com a prática educacional. Não deixa de ser sintomática a preocupação do educador para que o indivíduo se aproprie efetivamente das objetivações culturais pelas quais é mediata ou imediatamente responsável. Contudo, se esta apropriação necessita ser efetivada, devemos considerar as relações conflituosas estabelecidas entre os agentes da produção cultural, ou seja, entre os opressores e os oprimidos. De certa forma, essa dicotomia entre oprimidos e opressores reverbera o caldo cultural da época, onde imperava a discussão de uma cultura brasileira presente no âmago da relação entre colonizadores e colonizados. Com efeito, no Brasil dos anos 50 e 60 a discussão da problemática da consolidação de uma identidade nacional era fortemente marcada pelo ideário do ISEB, pelos Movimentos de Cultura Popular e pelo Centro Popular de Cultura da UNE. Para Renato Ortiz:

As filiações do pensamento de Paulo Freire com o ISEB são conhecidas. Vanilda Paiva mostra muito bem como a filosofia existencialista, o conceito de cultura e de popular orientam diretamente o seu método de alfabetização (Ortiz, 1985, p.48).

De fato, o livro de Vanilda Paiva intitulado: Paulo Freire e o Nacionalismo-Desenvolvimentista (1986) ilustra a forma como a proposta pedagógica do educador fundamenta-se - via mediação dos pensadores isebianos - no referencial teórico existencialista-cristão e culturalista e no ideário do nacionalismo-desenvolvimentista. Há uma consistente análise histórica que mostra como as idéias de Jaguaribe, Guerreiro Ramos, Álvaro Vieira Pinto, Roland Corbisier, entre outros, baseados nos escritos de pensadores tais como Jaspers, Fanon, Gabriel Marcel, Ortega y Gasset, Mannheim, influenciaram direta ou indiretamente os pressupostos teóricos de Paulo Freire. A influência dos membros do ISEB sobre as obras de Paulo Freire também é reconhecida por Vivian Schelling no livro: A presença do povo na cultura brasileira - ensaio sobre o pensamento de Mário de Andrade e Paulo Freire (cf. 1991, p.234). 
Os isebianos estavam preocupados em encontrar, no plano das idéias, as respostas necessárias para a explicação das crises culturais presentes nas circunstâncias históricas brasileiras da década de 50. Os nossos valores culturais encontravam-se em crise justamente porque, na interpretação dos membros do ISEB, estávamos deixando de ser uma nação semicolonial para nos transformar numa nação industrializada. Ora, a reformulação do ideário nacional fazia-se urgente, pois as nossas crenças e valores estavam se transformando. Não é à toa que Roland Corbisier fazia menção à existência de um complexo colonial que precisava ser solapado nos corações e mentes dos brasileiros. De acordo com o ideário isebiano, o complexo colonial seria a herança de um passado ainda presente, principalmente quando nos deparávamos com o comportamento "submisso e indolente" do brasileiro. A nação colonizadora utilizava-se da colônia como se fosse um mero instrumento capaz de atender às suas necessidades mais urgentes. Fazendo uso de conceitos da Fenomenologia do Espírito, Corbisier afirmava que: "O binômio senhor e escravo, que marca as relações entre o colonizado e o colonizador, nos parece caracterizar todo o complexo colonial" (cf. 1960, p.29).

Como contraponto a essa situação, todas as ideologias (aqui compreendidas como um conjunto de crenças e valores, representativos de várias classes e grupos sociais, tal como pensou Mannheim) que fizessem menção ao progresso e ao desenvolvimento seriam bem aceitas, pois se adequariam à mudança de fase pela qual passava o Brasil. E notória a forma como Guerreiro Ramos, baseado em Ortega y Gasset, classificava esse período de transição como sendo a passagem de uma sociedade natural (a sociedade colonial, sem consciência de si) para a sociedade histórica, representada pela sociedade industrial (cf. Paiva, 1986, p.41). É importante observar a forma como os membros do ISEB consubstanciaram os conceitos existencial-culturalistas com o objetivo de estabelecer as fundamentações teóricas da identidade nacional. Vanilda Paiva retrata essa constatação ao investigar a figura de Guerreiro Ramos. Freqüentemente, 
o isebiano fazia alusão ao projeto de construção dessa identidade nacional como sendo um projeto existencial, onde a nação também apresentaria as características de um ser para si, autoconsciente dos seus limites e de suas perspectivas. A possibilidade de um futuro melhor pautava-se na resolução da crise do espírito, ou seja, no engendramento dos valores e das crenças considerados "autênticos", o que significava dizer, vinculados ao projeto nacional-industrial-desenvolvimentista.

Na verdade, aquilo que Corbisier denominou de complexo colonial refletia não só uma atitude nacional. Essa sensação de subserviência estava presente na própria estrutura da personalidade do brasileiro. Vanilda Paiva demonstra que o pensador isebiano, novamente balizado em Ortega y Gasset e Gabriel Marcel, considerava os brasileiros, a exemplo dos seus vizinhos argentinos, ocos por dentro, justamente porque não tinham sido formados por uma cultura e por uma história próprias. Os tupiniquins possuíam suas interioridades ocupadas pelos mandos e desmandos de uma cultura exterior. Os valores e crenças dos senhores das metrópoles estariam mediando a forma como os brasileiros deveriam se sentir e comportar. Dessa forma, a propagação e a consolidação da alienação dificultaria sobremaneira o engendramento de uma cultura autêntica.

Nesse momento, seria interessante observar a forma como os alentos e as esperanças - fundamentadas no existencialismo e no culturalismo isebianas encontram ressonância nos escritos de Paulo Freire. Como se sabe, um dos conceitos centrais do pedagogo é o de hospedagem do opressor. Para deixar de ser o que são, os oprimidos precisam estar cônscios de que muitas vezes introjetam as normas e os valores que não são realmente deles, mas sim dos opressores. Poderíamos asseverar que há uma espécie de processo de colonização em jogo, muito bem ilustrado no combate à chamada consciência alienada. Certamente, notamos uma retórica muito semelhante com a dos isebianos, principalmente no que se diz respeito à noção de complexo colonial. Os brasileiros, de certa forma, estariam tão acostumados a ser verdadeiros sequazes dos ditames "estrangeiros" que teriam dificuldades em abandonar o 
ideano dos colonizadores e pensar por si próprios, desenvolvendo suas próprias crenças, valores e comportamentos, enfim, sua cultura "verdadeira". Paulo Freire diria que, nesse caso, há um forte sentimento que corresponde ao medo da liberdade. Na procura da consolidação de uma cultura autêntica, essa situação-limite (outro conceito que Freire utiliza dos existencialistasculturalistas, particulamente de Jaspers) necessitaria ser suprimida. O complexo colonial e o comportamento de subserviência precisariam ser superados e, para tanto, seria necessária a conscientização dos oprimidos, de que, na realidade, hospedam o opressor dentro de si. Caso contrário, contribuiriam para a reprodução da própria situação de opressão.

As "semelhanças" não param por aqui. Já na década de 60, Paulo Freire demonstrou claramente grande simpatia pelo nacionalismodesenvolvimentista. Da mesma forma que os isebianos, o autor da Pedagogia do Oprimido, utilizou-se do referencial existencial-culturalista para referendar suas esperanças em dias melhores, posto que o processo de industrialização e de democratização estava fornecendo as condições necessárias para que o Brasil se transformasse num ser para si. $\mathrm{O}$ autêntico ser brasileiro seria aquele que tivesse a consciência desperta para a análise da realidade nacional. Paulo Freire, no livro: Educação como prática da liberdade (1991), reconhece e elogia a transformação pela qual passou o ISEB, deixando de ser um reduto de intelectuais isolados numa redoma de cristal - locus de investigação da cultura erudita estrangeira — e passando à análise de nossas questões nacionais. Pode-se afirmar que a luta imperialista e anticolonialista fazia parte das intenções tanto de Paulo Freire como dos isebianos:

O caminho escolhido por Freire coincide exatamente com aquele eleito por Corbisier. A análise da "situação fundamental do homem" era para ambos o ponto inicial de uma reflexão que desemboca sobre o "pensar a história e a cultura" (Paiva, 1986, p.84).

A pedagogia e o método da proposta alfabetizadora de Paulo Freire teriam a função de propiciar subsídios para que os indivíduos e as suas organizações representativas exigissem, do Estado, as condições 
necessárias para o progresso e o desenvolvimento da própria nação. As crenças e os valores dos brasileiros estariam compatíveis com o processo de industrialização e urbanização iminente. $O$ brasileiro necessitaria ser reeducado, deixando para trás a chamada fase da consciência ingênua, ao atingir a fase da consciência crítica. Para tanto, uma nova proposta pedagógica seria de fundamental relevância. Assim, para Vanilda Paiva, da mesma forma como os isebianos objetivaram elaborar uma sociologia nacional (Guerreiro Ramos) e uma filosofia nacional (Roland Corbisier), Paulo Freire pretendia formar uma pedagogia nacional, consubstanciada às vidas das comunidades local e nacional.

Tanto as idéias nacionalistas isebianas, como a defesa intransigente de Paulo Freire despersonalização pautada numa ação refletida em todas as situações sociais, não passaram despercebidas pelos militares que posteriormente tomariam o poder em meados da década de 60 . Com a consolidação do regime militar, mais uma vez o Estado estabelece, de forma autoritária, a maneira pela qual o capitalismo iria se desenvolver no Brasil. É a institucionalização do chamado capitalismo tardio, com o Estado militar vinculado aos interesses do capital nacional e estrangeiro. Inicia-se uma fase de crescimento econômico, mediante empréstimos estrangeiros, e temse o progresso tecnológico enquanto principal meta a ser atingida.

Evidentemente, a esfera da educação não poderia ficar de fora desse contexto e do desejo de abandonar, finalmente, o rótulo indesejado de país "colonizado" e subdesenvolvido. Não é por acaso ser esse o período da história do Brasil que se caracteriza pela consolidação do mercado de produtos simbólicos.

\section{Não só indústria, não só cultura: o conceito de indústria cultural}

Antes mesmo de elaborar algumas considerações sobre o processo de incipiência, de produção e de consolidação da indústria cultural no Brasil, seria relevante fazer observações sobre o próprio conceito. De acordo com Adorno, o termo indústria cultural foi empregado pela 
primeira vez em 1947 no livro: Dialektik der Aufklarüng (traduzido no Brasil como Dialética do Esclarecimento, 1986, por Guido Antônio de Almeida). Os frankfurtianos substituíram o termo cultura de massa por indústria cultural com o intuito de descaracterizar uma cultura que surge espontaneamente das próprias massas, como se fosse uma forma contemporânea de manifestação artística popular. Na sociedade capitalista avançada, a produção e a reprodução da cultura, sob a égide da padronização e da racionalidade técnica, obedecem à mesma lógica da produção e da reprodução de qualquer outro tipo de mercadoria.

Adorno questiona se, em virtude do fim dos últimos resquícios dos sistemas pré-capitalistas, a sociedade capitalista estaria fadada a se desestruturar, mediante a instalação de um caos cultural decorrente da falta de instituições sociais que fossem responsáveis pela manutenção da ordem. Esse caos acaba por não se instalar, ou não se torna tão visível, principalmente em virtude da flexibilidade do sistema capitalista de produção em absorver quaisquer tipos de valores e comportamentos que, apriori, estariam em contradição com seus princípios gerais. Na verdade, Adorno chama a atenção para o fato de que a indústria cultural não é apenas indústria, pois se por um lado se assemelha a esta, em função de seguir os ditames da lógica da padronização e da racionalidade técnica, por outro lado também conserva sob o véu ideológico formas individuais de produção. E também não é apenas cultura, pois não conforma os produtos simbólicos de acordo com suas leis, mas em consonância com as leis de mercado (cf. Cohn, 1990, p. 11).

O processo de construção das "várias" identidades dos consumidores subsume-se cada vez mais aos ditames do mercado de produtos simbólicos que se por um lado proporciona a equalização e o reconhecimento mútuo entre as pessoas mediante a compra de um mesmo produto, por outro lado também permite a diferenciação ilusória, na medida em que destaca qualquer traço característico. De qualquer modo, a produção cultural torna-se cada vez mais massificada. Não obstante, o 
que acontece é a pseudodemocratização desses mesmos produtos (cf. Maar, Pucci, Costa, Zuin, 1995). O processo de massificação da produção cultural não significa uma democratização efetiva dessa produção, ainda que a maioria das pessoas possua alguma forma de acesso aos denominados produtos culturais. Na realidade, tal processo de massificação redunda na produção e na reprodução da semicultura. Este conceito significa que a apropriação cultural se realiza de forma deturpada, uma vez que a produção se subsume, como qualquer mercadoria, à lógica da padronização e da funcionalidade, em detrimento da emancipação e da objetivação de consciências criticas. De acordo com Wolfgang Leo Maar, para Adorno, o conceito de semicultura expressa:

... uma formação falsa enquanto processo formador da ilustração e sua articulação entre dominação e autonomia, porque não dotada do momento emancipador, da autonomia (Maar, 1992, p. 186).

O termo semicultura parece ser o mais adequado a esse processo educacional, onde a instrumentalização da produção simbólica predomina em relação à dimensão emancipatória presente na própria racionalidade. Antes de significar o produto uma crise das teorias pedagógicas, observase que o indivíduo semiculto é representativo de um tempo em que a capacidade de memorização e a própria noção de historicidade se encontram cada vez mais solapadas. No dominio da indústria cultural, a lógica do equivalente, presente na produção das mercadorias, não se restringe aos processos de produção, mas espraia-se, inclusive, para a esfera da educação e da produção da cultura (cf. Adorno, In: Ramos de Oliveira, 1992).

A reprodução da semicultura pode ser identificada como a forma de produção e reprodução dos produtos simbólicos na chamada sociedade globalizada. Os militares sabiam que a tão sonhada construção da identidade nacional brasileira teria que ser alcançada mediante sua subordinação à lógica de produção que sobrepujava as decantadas forças "nacionais". O nacional seria confirmado mediante a subsunção ao 
internacional. Isso significa queja podemos notar, nas últimas décadas, o crescimento de urna tendencia contida na essência do capitalismo desde o seu nascimento, ou seja, a de espraiar seu modus operandi e seu modus vivendi a todas as partes do planeta. Evidentemente, a concretização desse fato encontra auxílio decisivo no desenvolvimento da tecnologia. Talvez essa associação entre desenvolvimento tecnológico e progresso encontre seu ápice durante a instalação e a reprodução do governo militar no nosso País. São, portanto, estruturadas as condições objetivas para a consolidação da indústria cultural no Brasil.

\section{O processo de mercantilização dos produtos simbólicos no Brasil}

Feitas essas considerações sobre o conceito de indústria cultural, seria importante retornar à análise, ainda que superficial, a respeito do seu processo de instalação, reprodução e consolidação em nosso país. No livro A Moderna Tradição Brasileira, Renato Ortiz faz uma série de pertinentes considerações a esse respeito. De acordo com o autor, apesar de toda a efervescência cultural e política que agitava o Brasil nas décadas de 30 a 50, em busca de uma identidade nacional, a sociedade brasileira era ainda fortemente marcada pelo localismo. Essa é uma característica predominantemente impeditiva para a consolidação da indústria cultural, pois é necessária uma completa integração sociocultural e, por que não dizer, política. Obviamente, existia por parte do Estado uma vontade de unificação do setor cultural; basta observar as medidas de Capanema na esfera educacional:

As medidas de Capanema na esfera educacional visavam justamente a esse resultado. A ideologia da Educação Moral e Cívica veiculada nas escolas tinha como pressuposto a necessidade de construir a nacionalidade através de atividades pedagógicas (Ortiz, 1991. p.49-50).

Mas, principalmente em virtude de condições materiais precárias, a indústria cultural encontra dificuldades em se expandir. Com o predomínio 
dessas características, não é de se admirar que durante esse processo conturbado de sua consolidação possam ser engendradas manifestações culturais tais como a do Cinema Novo, na década de 60, que ainda se contrapõem estética e politicamente ao processo de industrialização, no caso, o cinematográfico. Em meados dessa década, com o golpe militar, o Estado brasileiro impõe a si mesmo a tarefa de integração nacional, reconhecendo, para tanto, a importância dos meios de comunicação de massa na difusão e na consolidação de uma identidade nacional. São, então, fornecidos subsídios materiais e técnicos para a expansão dos meios de comunicação em rede nacional. Não é fato desconhecido de ninguém que, justamente neste período, a própria Rede Globo notabilizou-se como aliada do Estado autoritário brasileiro e que cresceu muito em função disso. $\mathrm{O}$ caráter nacionalista é facilmente evidenciado nas frases da época tais como: "Brasil, ame-o ou deixe-o" ou então no trecho do hino da seleção brasileira na copa de 70: "Noventa milhões em ação, pra frente Brasil do meu coração... De repente é aquela corrente pra frente". A própria utilização da palavra corrente é bem sugestiva. Assim, o Estado autoritário brasileiro assume a direção do processo de desenvolvimento do capitalismo em sua fase mais avançada, devidamente cooptado com os empresariados nacional e multinacional. Renato Ortiz alude para o fato de que:

Ambos os setores vêem vantagens em integrar o território nacional, mas enquanto os militares propõem a unificação política das consciências, os empresários sublinham o lado da integração do mercado (Ortiz, 1991, P 118).

Dessa maneira, os anos 60 e 70 caracterizam-se pela consolidação do mercado de produtos simbólicos no Brasil. Nesse período da história brasileira, a indústria cultural desempenha uma importante função no sentido de propiciar a integração e o conformismo social. São criados vários programas sociais que intencionavam diminuir a imensa defasagem de formação educacional do Brasil, em comparação com os chamados 
países do primeiro mundo. São famosos os chamados "produtos culturais", tais como os telecursos e as revistas especializadas, que tentam compensar "culturalmente" uma enorme faixa da população brasileira.

Não obstante, tanto um quanto outro produto cultural possuem como principal característica a superficialidade com que abordam os mais variados temas - ciências, artes, política etc.- , propagando-se a ilusão de que as pessoas estão bem informadas sobre os mais variados assuntos. Para esse individuo semi-aculturado, torna-se cada vez mais dificil a conscientização de que sua formação educacional possui falhas visíveis, dada a rapidez com que consome informações facilmente descartáveis e que apenas contribuem para a reprodução da invisibilidade de sua própria vida debilitada.

Quanto aos alunos que permanecem inseridos no sistema escolar, é comum observar os pressupostos da semicultura - baseada na lógica da padronização e da racionalidade técnica -, mediando as mais variadas situações escolares. Algumas dessas situações são aquelas nas quais os alunos competem entre si com todo o vigor, decorando fórmulas e dados históricos, na esperança de vislumbrarem seus nomes nas listas dos melhores alunos, fixadas mensalmente nos murais das escolas.

Outro exemplo diz respeito às competições esportivas que, ao invés de estimularem a solidariedade e o espírito de comunidade, estimulam a competição desenfreada e a vitória a qualquer custo. Ao vencedor, a glória; ao perdedor, a vergonha e a humilhação. Essa é a lógica implacável que reina incólume nas escolas e que está em total consonância com a lógica dual e competitiva que permeia todas as relações da nossa sociedade.

$\mathrm{Na}$ ânsia pela aprovação nos exames que perpassam toda a trajetória escolar, os alunos absorvem os conhecimentos de forma alucinada, pois sabem que são valorizados como "bons aprendizes", quando conseguem decorar fórmulas e acontecimentos sociais, que serão facilmente esquecidos num curto espaço de tempo. Na realidade, o sucesso ilusório obnubila apenas superficialmente o perene fracasso que caracteriza o sistema educacional como um todo. 


\section{A problematização de conceitos da pedagogia do oprimido no contexto da industria cultural}

É relevante enfatizar que o pròprio Paulo Freire reconhece que, para o oprimido se transformar em sujeito de suas ações, é fundamental o rompimento dessa aderência, dessa imediaíez com que se defronta na realidade, a fim de poder problematizá-la objetivamente. Quando o sujeito entra em contato com o mundo, ocorre uma certa objetivação da sua subjetividade, o que implica uma relação de inadequação, de distanciamento, bem como a conseqüente apropriação dessa subjetividade, quando se realiza seu processo de adaptação. Nesse processo de construção da experiência formativa, de acordo com o educador, faz-se cada vez mais necessário que o oprimido participe efetivamente do seu contínuo processo de formação da condição de sujeito, baseado numa relação dialógica com o educador, mediante a investigação do objeto cognoscível.

Se a concretização dessa experiência necessita dessa articulação dialógica, contudo, o que se observa cotidianamente é a produção e a reprodução de um processo semicultural que solapa nas suas próprias bases as condições de continuidade e temporalidade, presentes na relação sujeitoobjeto. Essas condições são fundamentais para a consolidação do exercício da reflexão crítica, que se encontra "travada", em virtude das exigências internas de uma sociedade baseada no fosso cada vez mais profundo entre o prometido e o efetivamente cumprido. Em face desse contexto, como pensar essa necessidade de continuidade e de temporalidade, já que atualmente o que conta é o consumo cada vez mais voraz de informações que devem ser absorvidas no menor espaço de tempo?

E notória a velocidade com que os novos conhecimentos são produzidos, bem como as exigências para que a adaptação aconteça também o mais rapidamente possível. Numa sociedade cujo progresso das forças produtivas ocorre num ritmo vertiginoso, rompem-se definitivamente os grilhões das correntes que nos mantêm vinculados com 
o passado que propiciou essa mesma situação? A defesa de Paulo Freire pela apropriação efetiva dos produtos culturais, uma vez que o oprimido identifica-se como membro participante do processo histórico dos fracassos e sucessos que marca a humanidade, é incompatível com o progresso tecnológico e com a forma como transcorre a racionalidade técnica? Poderíamos dizer que, baseados nos escritos de Paulo Freire, não haveria incompatibilidade com o progresso per se, ou seja, com o fato de que o homem desenvolva cada vez mais suas capacidades, na perene busca da liberdade, diante do processo de satisfação de suas necessidades materiais e espirituais. Porém, certamente o educador não concordaria com a intensificação de uma racionalidade que visa quase que exclusivamente à realização do lucro e que legitima a distribuição e a reapropriação desiguais dos produtos culturais.

Uma condição fundamental para a Pedagogia do Oprimido referese à efetiva apreensão, por parte dos agentes educacionais, dos temas geradores, que propiciarão o processo de problematização da própria realidade, na medida em que os agentes educacionais se conscientizem das situações que limitam a concretização das suas capacidades. Daí a importância, destacada por Paulo Freire, de que os oprimidos necessitam compreender que essas situações-limiíe fazem parte de uma totalidade que precisa ser problematizada. Ora, se a apreensão crítica dos temas geradores por parte dos agentes é central para a condição de que venham a ser sujeitos e não objetos, o que dizer de uma sociedade onde já no consumo dos produtos simbólicos podemos observar as respostas para todas as perguntas, e até mesmo as prescrições de como é que os homens devem se comportar nas mais "diferentes" situações?

E justamente nesse ponto que podemos observar que a mercantilização dos produtos simbólicos, fato que marca a consolidação da indústria cultural no Brasil, implica uma realidade dificilmente de ser contestada ou mesmo evitada. $\mathrm{O}$ fascínio exercido pelo contato com as novidades tecnológicas cada vez mais sedutoras, tais como os computadores e os telefones celulares, não pode obnubilar o fato de que 
cotidianamente nos deparamos com produtos "culturais" cujas mensagens de como devemos nos comportar e pensar já se encontram embutidas nos seus interiores. E, mais do que isso, no decorrer do consumo desses mesmos produtos, aliviamos a nossa debilidade e todas as frustrações cotidianas quando nos sentimos, de forma ilusória, os senhores de nossas ações e da própria realização de nossos desejos.

Num país tal como o nosso, onde podemos observar deficiências profundas no processo de formação cultural, pois nos deparamos com milhões de pessoas que não são sequer alfabetizadas, a reprodução de um sistema de desigualdades sócias torna-se cada vez mais possível, posto que se produz de forma mais sutil. Mesmo aqueles que podem ser considerados alfabetizados dificilmente deixam de estar inseridos na lógica desse processo. A produção da semicultura tende a uniformizar todas as possíveis diferenças, pois o mercado de produtos "culturais" atinge todas as camadas sociais. Evidentemente, em face dessa situação recente, uma vez que a consolidação da indústria cultural no Brasil pode ser observada apenas nos últimos 30 anos, encontramos uma série de dificuldades na investigação desse processo. Não obstante, deve-se considerar que as situações que limitam o exercício da reflexão são atualmente muito mais difíceis de serem visualizadas, apesar de todo o predomínio - nesse momento histórico que marca a hegemonia das imagens - do olhar sobre os nossos demais sentidos. Como vimos, o próprio contato com a instrumentalização do alfabeto não é per se suficiente para que o indivíduo possa se reconhecer como oprimido e assim lutar para a concretização do inédito viável.

O próprio Paulo Freire reconhece que a mera instrumentalização não significa o fim da debilidade. Na própria história do Brasil, pudemos observar no que redundou a tentativa do Mobral em utilizar o método de alfabetização de adultos como se fosse uma "técnica" qualquer, neutralizando sua dimensão política. Por outro lado, a problematização de nossa totalidade não pode desconsiderar hoje o fato de que a produção cultural no Brasil está subsumida aos ditames da mercantilização da 
produção em escala global. Ora, tal fato implica o questionamento das promessas de felicidade que nunca são cumpridas e que estão imanentemente vinculadas aos produtos "culturais". Caso contrário, podemos ter a ilusão de que somos sujeitos, quando na verdade reforçamos nossa condição de objetos.

Além disso, há que se destacar o questionamento de Paulo Freire a respeito da participação dos oprimidos na produção e na reprodução da violência. Para o educador, os oprimidos nunca poderiam ser os responsáveis pelo início da barbárie, uma vez que eles são seu resultado. Se Paulo Freire tem razão, o que dizer do fato de que muitas vezes são os próprios oprimidos os responsáveis pela perpetuação do próprio processo de desumanização? $\mathrm{O}$ educador poderia responder que nesses casos os oprimidos não identificaram ainda os opressores neles hospedados e se comportam de maneira ambígua, pois o ser mais está correspondendo ao ter mais, de forma egoísta e desumana. Contudo, como pensar essa dicotomia entre opressores e oprimidos numa sociedade tal como a nossa, onde a lógica do equivalente vai permeando cada vez mais todas as relações sociais?

Essa lógica do equivalente permeia, inclusive, relações que aparentemente estariam isentas de tal influência. Basta observarmos como as relações afetivas, por exemplo, estão sujeitas à subordinação dos ditames da mercantilização. Freqüentemente, avaliamos o quantum de afeto que as pessoas sentem entre si em função da quantidade de dinheiro disponível para a compra de presentes. O ser mais parece equivaler ao ter mais em todas as camadas sociais. Desta forma, a dicotomia entre opressores e oprimidos precisa ser novamente pensada em outro prisma. Não há mais como imaginá-la sob a forma de pólos opostos. O desejo de realização pessoal, mediante o consumo de produtos semiculturais, não pode ser atribuído somente aos opressores ou aos oprimidos que os hospedam dentro de si mesmos.

Se observarmos novamente essa relação entre oprimidos e opressores no plano da consolidação de uma identidade nacional, a ânsia que até bem pouco tempo atrás caracterizava o ímpeto brasileiro para a 
construção de sua identidade fundamentava-se quando negava a produção cultural estrangeira em nome de um produção cultural eminentemente nacional. Atualmente, é dificil pensarmos nosso vínculo com os demais países somente pela caracterização de uma relação entre uma nação semicolonial e as demais nações industrializadas. No plano da produção simbólica, essa discussão deve ser repensada, pois se constata a presença de um certa "autonomia" na produção cultural brasileira e que segue à risca os padrões desejados para sua realização enquanto mercadoria, tanto no Brasil como no exterior. É notório o caso das novelas brasileiras que são exportadas, fazendo grande sucesso em todas as partes do globo. Quanto aos escritos de Paulo Freire, seria ingênuo afirmar que, para o educador, os opressores e os oprimidos representam pólos que não se relacionam. O próprio conceito de hospedagem do opressor já caracteriza sua intenção de relacionar dialeticamente ambos os grupos.

Paulo Freire observou a vontade com que os oprimidos, que não estão conscientes daquilo que representam para si mesmos e para seu grupo, desejam se transformar em opressores. Contudo, na sociedade brasileira atual, a reificação das consciências recrudesce de tal forma que a lógica da equivalência generaliza-se para todas as camadas sociais, deixando de ser apenas um atributo dos opressores ou dos oprimidos que ainda não estão cônscios de si mesmos. Ao deslocarmos esta relação para o plano da discussão de uma identidade nacional, percebe-se que a dicotomia entre colonizados e colonizadores, que até bem pouco tempo caracterizou as preocupações dos intelectuais do ISEB, necessariamente precisa ser revista, em virtude dessa nova realidade, ou seja, a realidade da consolidação da indústria cultural no Brasil. De acordo com Renato Ortiz,

... esse fato (a mercantilização dos produtos simbólicos nacionais, ajustada aos padrões internacionais) marca uma etapa da sociedade brasileira onde se torna impossível retornarmos à antiga oposição colonizador/colonizado com a qual estávamos habituados a operar, a menos, é claro, que queiramos confundira idéia de realização da liberdade com as formas de dominação da sociedade industrial "nacional" (Ortiz, 1991, p.206). 
Evidentemente, as diferenças sociais estão aumentando cada vez mais, a ponto mesmo de nos tornarmos indiferentes se temos 32 ou 31 milhões de marginalizados, como se um milhão de pessoas não fizesse alguma diferença. Entretanto, se podemos observar a acentuação das desigualdades sociais, não podemos ficar indiferentes ao fato de que a reprodução da indústria cultural no nosso país, antes de significar o acesso coletivo aos produtos "culturais", representa, principalmente na dimensão da psique, a consolidação da ilusão de que todos são sujeitos na ação de consumo, quando, na verdade, se afirmam cada vez mais como objetos. Ao comentar a relação entre dominados e dominantes. Adorno já dizia que as diferenças psicológicas entre as classes parecem ser bem menores em comparação com as diferenças materiais objetivas (cf Adorno, 1992, p. 160).

Por outro lado, o processo de estultificação das consciências e da reprodução da debilidade não ocorre de forma a eliminar as resistências daqueles que se encontram cada vez mais impossibilitados de assimilar criticamente a produção dos bens culturais. Historicamente, a subsunção dos incipientes proletários à lógica da obtenção do lucro, mediante a venda de sua própria força de trabalho, bem como o processo de expropriação do saber não aconteceram de maneira harmônica. Pelo contrário. Contudo, com a globalização das relações de produção capitalistas, e com a crescente heteronomia do valor de troca sob o valor de uso, observa-se a presença dessa lógica que impera nas relações de mercado na própria consciência e, principalmente, na esfera do inconsciente. $\mathrm{O}$ exemplo das relações afetivas exposto acima retrata bem esta asserção. Essa subjetividade, que se encontra cada vez mais reificada, é cotidianamente nutrida mediante o consumo desses produtos semiculturais, que acabam por atenuar sua fraqueza e reafirmar a constatação do sempre igual e do "natural". Adorno afirma que, nesses tempos do controle da fantasia e da imaginação, os produtores e executores da indústria cultural sabem muito bem que devem ser oferecidas certas condições materias básicas, que possibilitem com que as pessoas tenham os subsídios mínimos para o consumo dos produtos semiculturais. Caso contrário, revoltas podem vir a ocorrer. 
Ora, se a consolidação do mercado de produtos simbólicos no nosso país é um fato, como imaginar essa condição sine qua non, na medida em que o próprio acesso a esses produtos se encontra cada vez mais negado? Uma tentativa de resposta a esta pergunta seria a de que, também em nosso país, quase ninguém acaba sendo esquecido, pois haverá, de alguma forma, algum tipo de produto que oferecerá a compensação momentânea da própria ilusão. Não é insignificante o fato de que, para a maioria da população brasileira, o contato com a televisão ocupa grande parte do tempo diário. São comuns atitudes de indivíduos que controlam o tempo de suas atividades, de acordo com os parâmetros estabelecidos pela televisão.

Estamos sofrendo profundas transformações nas noções de espaço e de tempo em virtude das modificações das forças produtivas, sem que tenhamos consciência disso. Não obstante, as debilidades psíquicas e materiais precisam ser atenuadas de alguma maneira. E sintomática a constatação de que as pessoas projetam seus desejos nos personagens da televisão, que parecem realizar todas as atividades cotidianamente negadas no dia-a-dia dos consumidores. O que não deixa de ser problemático é que o fictício exercício da cidadania se baseia na ilusão associativa de que a sensação de liberdade das pessoas depende delas agirem da mesma forma que as personagens de novela, por exemplo, que representam seus "ativos" papéis perante o manuseio dos produtos, cujos rótulos clamam pela necessidade de serem imediatamente consumidos. Mas, se a fantasia é controlada de maneira perversa, isso não ocorre de forma que o indivíduo e/ou o grupo social não possam questionar as maneiras pelas quais os homens produzem sua existência, assim como a distribuição dos bens produzidos.

Se os produtos espelham os desejos dos homens, possibilitandolhes o reconhecimento como seres humanos, deve-se, no entanto, questionar os tipos de relações estabelecidas que, no limite do processo de reificação, acabam por imputar às mercadorias o poder de ditar as formas de comportamento e de pensamento aos próprios criadores. As 
forças sedutoras que as imagens dos produtos semiculturais exercem sobre as pessoas não podem ser desconsideradas, sobretudo num país cujas imensas debilidades - material e espiritual — são, de certa forma, compensadas no ritmo alucinante de absorção do brilho dos simulacros e na perpetuação do desejo de uma vida mais humana. Diante desse contexto, deve-se permanecer sensível ao fato de que a esperança de dias melhores pode perder sua força, em virtude do exercício de nosso conformismo e de nossa dessensibilização diante das atrocidades que insistem em lembrar quem somos na realidade.

\section{Conclusões}

O resgate de conceitos tais como hospedagem do opressor, siiuação-limiíe, sombra, inédito viável e experiência educacional dialógica torna-se fundamental para a crítica de uma educação balizada na absorção de conhecimentos e de valores não visíveis à primeira vista, e cuja introjeção auxilia no processo de produção e reprodução da barbárie. O ethos que medeia tanto a Pedagogia do Oprimido como a Pedagogia da Esperança deve ser reconhecido, no sentido de valorização da defesa de uma efetiva reapropiação dos produtos culturais. A verdadeira experiência formativa é aquela que propicia ao indivíduo se reconhecer no produto construído, quando se sente membro participante do processo histórico. $\mathrm{O}$ reconhecimento de uma perspectiva humanista histórica presente nos escritos de Paulo Freire faz-se cada vez mais atual. Principalmente porque se valoriza, atualmente, muito mais o aspecto instrumental e funcional da produção "cultural" do que ponderações éticas e juízos de valor que possam questionar a forma como estes produtos "culturais" são engendrados, bem como os interesses mercadológicos que estruturam o processo de distribuição e apropriação dos mesmos. Em tempos em que a massificação dos produtos semiculturais se torna uma constante nas mais variadas situações sociais, o resgate e a investigação dos pressupostos 
teóricos desenvolvidos por Freire representam a permanência do inconformismo diante da reprodução da barbárie. Porém, deve-se considerar que esses mesmos conceitos necessitam ser repensados, sobretudo pelo fato da consolidação da indústria cultural no nosso país e no plano global.

Paulo Freire insiste que não se pode desconsiderar as representações, os desejos, os sentimentos e os conhecimentos das pessoas pertencentes às camadas populares. Para tanto, cita a etnociência, no sentido de "evitar a dicotomia entre esses saberes, o popular e o erudito, ou de como compreender e experimentar a dialética entre o que Snyders chama de "cultura primária" e "cultura elaborada":

Respeitar esses saberes, de que falo tanto, para ir mais além deles, jamais poderia significar... dever ficar o educador ou a educadora aderida a eles, os saberes de experiências feitos... O respeito, então, ao saber popular implica necessariamente o respeito ao contexto cultural. A localidade dos educandos é o ponto de partida para o conhecimento que eles vão criando do mundo. "Seu" mundo, em última análise, é a primeira e inevitável face do mundo mesmo... Assim como é errado ficar aderido ao local, perdendose a visão do todo, errado é também pairar sobre o todo sem referência ao local de onde se veio (cf. Freire, 1993, p.86-87).

De certa forma, podemos observar raciocínio semelhante na análise da linguagem machista que norteia — Paulo Freire chama a atenção para o conteúdo ideológico presente na palavra nortear, a saber: a imposição de diretrizes do Norte, que é o primeiro mundo (cf. 1993, p.218) - o nosso comportamento cotidiano e que reforça, nas palavras do autor, uma prática colonial. Ao meu ver, essas asserções corroboram o argumento de que o educador mantém na Pedagogia da Esperança, de forma geral, o mesmo raciocíonio desenvolvido na Pedagogia do Oprimido, ao destacar as relações conflituosas entre opressores e oprimidos, entre colonizadores e colonizados e suas respectivas "culturas". Diante dessa constatação, fazem-se relevantes algumas questões: será que atualmente podemos fazer referência a dois 
supostos conteúdos culturais, pertencentes a duas classes diferenciadas, da mesma forma como foi feito na década de 60? Será que podemos falar atualmente de um saber de experiência feito que seja originário de um autêntico saber popular? Ambas as chamadas culturas popular e erudita encontram-se isentas do processo de mercantilização dos produtos simbólicos? E mais, será que, atualmente, podemos nos referir às culturas exclusivamente nacionais e estrangeiras, quando tratamos de investigar a forma de produção e de assimilação dos produtos semiculturais?

Este trabalho procurou fornecer alguns subsídios iniciais para tentativas de respostas às questões feitas acima. Chegamos a um período em que a principal contradição que acompanhou a própria humanidade atinge patamares notáveis, ou seja, a contradição de que a expansão de nossas potencialidades pode gerar circunstâncias que nos limitam cada vez mais. Não podemos deixar de reconhecer que estamos experienciando o contexto da sociedade cuja produção cultural se encontra globalizada. Isso significa que temos que refletir sobre as relações de dominação em outras condições. Não devemos mais ficar restritos à análise das antinomias entre saber popular e saber erudito, opressor e oprimido, colonizador e colonizado, tendo por base apenas o referencial epistemológico relacionado ao projeto de construção de uma identidade nacional, tal como aquele desenvolvido no período entre meados de 50 e de 60. As questões educacionais, bem como as relações de opressão, precisam ser repensadas, pois a indústria cultural, no plano global, se consolida gradativamente como principio pedagógico por excelência. Isso não significa a total uniformização dos comportamentos e dos pensamentos. Certamente, as nações e suas respectivas regiões assimilam a universalização da produção simbólica de forma diferenciada. Contudo, isso não quer dizer que devamos evitar investigar as conseqüências, no nosso pais, da universalização do capital e do seu ethos, pois teríamos que continuar atrelados ao estudo exclusivo da nossa "sociedade nacional". $\mathrm{Na}$ verdade, vivemos numa sociedade incrivelmente transformada e que impinge estilos de vida, sentimentos e formas de educação não mais restritos ao locus nacional, mas que dizem respeito a padrões de comportamentos e valores globalizados, rearticuladores do próprio local e formadores de novas tradições. 
Referencias bibliográficas

ADORNO, T.W., HORKHEIMER, M. Dialética do esclarecimento. Tradução de Guido Antonio de Almeida. Rio de Janeiro: Zahar, 1986.

ADORNO, T.W. Minima Moralia. Tradução de Luiz Educado Bieca. São Paulo: Ática, 1992.

Teoria da semicultura. Tradução de Newton Ramos de Oliveira, Bruno Pucci e Claudia Abreu. In: RAMOS DE OLIVEIRA, N. Theodor Adorno: quatro textos clássicos. São Carlos: UFSCar, 1992.

BUFFA, E., NOSELLA, P. A educação negada, introdução ao estudo da educação brasileira contemporânea. SãoPaulo: Cortez, 1991.

COHN, G. Dificil reconciliação: Adorno e a dialética da cultura. In: Lua Nova. n. 20, maio 1990.

CORBISIER R. Formação e problema da cultura brasileira. Rio de Janeiro: ISEB, 1960.

COSTA, B. Indústria cultural: análise crítica e suas possibilidades de revelar ou ocultar a realidade. In: PUCCI, B.(Org). Teoria crítica e educação, a questão da formação cultural na escola de Frankíurt. Petrópolis, Rio de Janeiro: Vozes, 1995.

FREIRE, P Ação cultural para a liberdade. Rio de Janeiro. Paz e Terra, 1987. Terra, 1991. Educação como praticada liberdade. Rio de Janeiro: Paz e Educação e mudança. Rio de Janeiro: Paz e Terra, 1986.

FREIRE, P. Pedagogia da esperança. Rio de Janeiro: Paz e Terra, 1991. Pedagogia do oprimido. Rio de Janeiro: Paz e Terra, 1979. 
FREIRE, P., SHOR, I. Medo e ousadia. Rio de Janeiro: Paz e Terra, 1987.

GADOTTI, M. Educação e poder: introdução à pedagogia do conflito. SãoPaulo: Cortez, 1988.

GIROUX, H. Teoria crítica e resistência em educação. Tradução de Angela Maria B. Biaggio. Rio de Janeiro: Vozes, 1986.

MAAR, W, Leo. Lukàcs, Adorno e o problema da formação. In: Lua Nova, n.ll, 1992.

ORTIZ, R. Cultura brasileira e identidade nacional. São Paulo: Brasiliense, 1985.

A moderna tradição brasileira São Paulo : Brasiliense, 1991.

PAIVA, V Paulo Freire e o nacionalismo-desenvolvimentista. Rio de Janeiro: Civilização Brasileira, 1986.

PUCCI, B (org). Teoria crítica e educação: a questão da formação cultural na escola de Frankfurt. Petrópolis: Vozes, 1995.

SCHMIED-KOWARZIK, W. Pedagogia dialética: de Aristóteles a Paulo Freire. São Paulo: Brasiliense, 1983.

SHEELLING, V A presença do povo na cultura brasileira: ensaio sobre o pensamento de Mário de Andrade e Paulo Freire. Tradução de Federico Carotti. Campinas: UNICAMP, 1991.

ZUIN, Antonio Álvaro. Seduções \& simulacros: considerações sobre indústria cultural e os paradigmas da resistência e da reprodução em educação. In: PUCCI,B. (Org.). Teoria crítica e educação: a questão da formação cultural na escola de Frankfurt. Petrópolis: Vozes, 1995. 
Recebido em 29 de novembro de 1995.

Antônio Álvaro Soares Zuin é psicólogo, graduado pela Universidade de São Paulo (USP), Campus de Ribeirão Preto; mestre em Educação pela Universidade Federal de São Carlos (UFSCar); doutorando em Ciências Sociais Aplicadas à Educação pela Universidade Estadual de Campinas (Unicamp) e professor-assistente do Departamento de Educação da UFSCar. É também membro do grupo de pesquisa: "O Potencial Pedagógico da Teoria Crítica III", da UFSCar, coordenado pelo professor Bruno Pucci e financiado pelo CNPq.

This article aims at discussing some concepts of the Pedagogy of the Oppressed in the context of the consolidation of the Culture Industry in Brazil. "Lodging the oppressor ", "to be more and to be less", "oppressor and oppressed", "popular culture and erudite culture" — these are concepts to be reinvestigated. This study becomes particularly relevant with the fact that the standardization of the symbolic production, as well as the universalization of the logic of equivalence intensify the individual's behaviors and these in an illusory way attenuate their weaknesses as they identify themselves as consumers.

$L$ 'objectif de cet article est la discussion des concepts de la Pédagogie de l'Opprimé dans le contexte de la consolidation de l'Industrie Culturelle au Brésil. Ilfaut reflechir aux conceptions telles que: "auberge de l'oppresseur ", "êtreplus et être moins ", "oppresseurs et opprimés ", "culture populaire et culture cultivée ". L 'étude est importante surtout parce que la standartization de la production symbolique de même que l'universalization de la logique de l'équivalent ont fait accroître les comportements des individus que d'une façon illusoire réduisent leurs faiblesses parce qu 'ils deviennent des consommateurs. 
Este artículo discute los conceptos de Pedagogía del Oprimido nel contexto de la consolidación de la Indùstria Cultural. "Hospedaje del opresor", "ser más y ser menos", "opresores y oprimidos", "cultura popular y adtura erudita " son conceptos que precisan ser reinvestigados. Este estudio resulta relevante, sobre todo, por el hecho de que la padronización de la producción simbólica, asi como la universalización de la lógica del equivalente intensifican los comportamientos de los individuos, los cuales atenúan ilusoriamente sus debilidades cuando identificados como consumidores. 